\title{
Practical Use of the Braking Attributes Measurements Results
}

\author{
Ján Ondrušs ${ }^{1, *}$, and Eduard Kolla ${ }^{2}$ \\ ${ }^{1}$ University of Žilina, Department of Road and Urban Transport, Univerzitná 8215/1, 01026 Žilina, \\ Slovak Republic \\ ${ }^{2}$ Institute of Forensic Research and Education of University of Žilina, Ulica 1. mája 32, 01001 Žilina, \\ Slovak Republic
}

\begin{abstract}
This contribution deals with issues of braking the passenger car. The measurement of braking deceleration of the vehicle Kia Cee'd 1,6 $16 \mathrm{~V}$ was carried out by an optical device Correvit system. The measurement was carried out on the airport of the village of Rosina located close to Zilina. 10 drivers of different age, praxis, and kilometers driven participated in the measurement. The measured process was the vehicle full braking with the service brake of the initial speed of approximately 50 $\mathrm{km} \cdot \mathrm{h}^{-1}$. Each of the drivers had 10 attempts. In the closure of this contribution the results of the performed measurements, their evaluation and comparison are presented. Practical result from the contribution is mainly the measurement set of braking deceleration of the respective vehicle during intensive braking.
\end{abstract}

\section{Introduction}

The braking deceleration value during intensive braking belongs to the important input data of the accident analysis. Only a small number of measurements made with the vehicles on common roads is published in the relevant literature. In this article the authors present their measurements results [1].

\section{The experimental vehicle}

A passenger car Kia Cee'd 1,6 16 V, production year 2008, belonging to the laboratories of the Department of Road and Urban Transport of the University of Žilina, was used as an experimental vehicle. During the trials the vehicle was loaded with two persons (a driver and a passenger who operated the measuring device). The experimental vehicle is shown in Fig. 1.

Tires Michelin Energy had dimension 185/65/R15 $88 \mathrm{H}$. The front tires tread depth was $6.1 \mathrm{~mm}$ and the rear tires tread depth was $6.3 \mathrm{~mm}$. At the time of the measurement the tires were pumped up to reach the compression specified by the producer, which was $220 \mathrm{kPa}$. The vehicle was equipped with the disc brakes on all wheels.

\footnotetext{
*Corresponding author: jan.ondrus@,fpedas.uniza.sk
} 


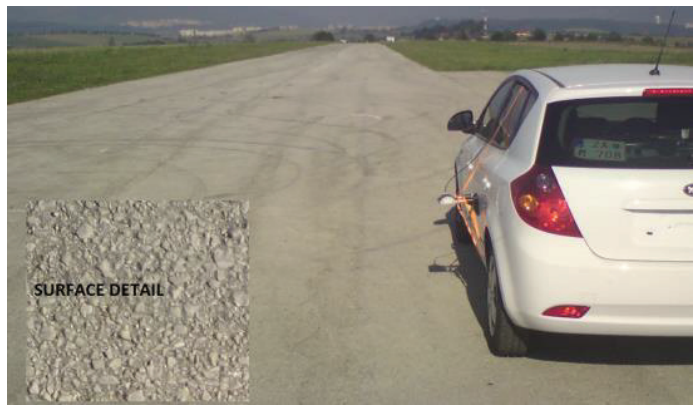

Fig. 1. The experimental vehicle. Source: authors

\section{Measuring equipment}

As the measuring device and recorder during the braking deceleration was used Correvit produced by the Corssys Datron. It is an optical device for measuring the braking deceleration process. This device consists of 4 main parts - microwave sensor, braking sensor, evaluation unit and control panel (fig. 2). The microwave sensor consists of sensor head and sensor electronics and accommodates additional connections, such as an interface for flow-measurement systems (for consumption tests), or trigger inputs for light barriers or brake switches, providing exceptional testing power and flexibility. The microwave sensor accommodates a precise, reliable and contactless measurement of the speed and length, using a technology based on a Doppler Effect [2-4]. To further identify additional data were, among others, used the devices for initial speed measuring - light barriers, cones, measuring tape, camera, camcorder, touch thermometer, slide calliper and notebook.
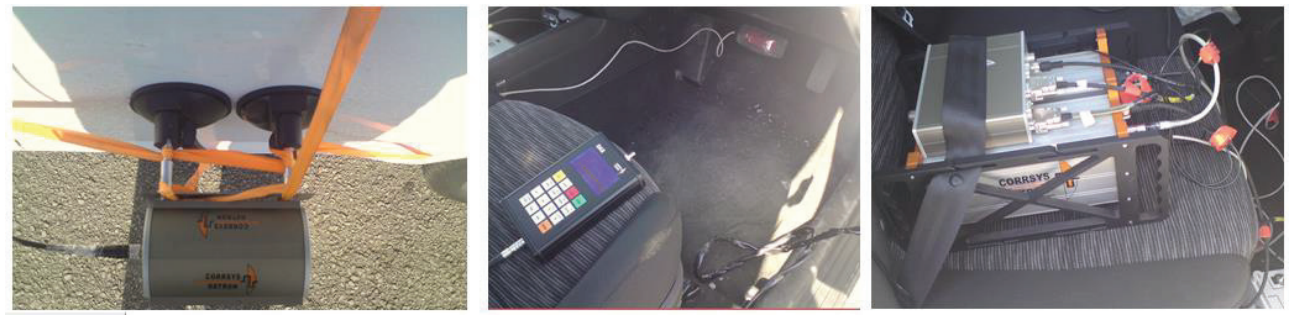

Fig. 2. Correvit - microwave sensor, evaluation unit, braking sensor and control panel. Source: Authors

The unit perceives the relative movement between itself and the test surface using a planar antenna, which projects two radar beams at $45^{\circ}$ angles. Upon striking the test surface, the beams are reflected back to the sensor antenna. The resulting double frequency (equal to the difference of sent and received frequencies) is directly speed-proportional. The two-beam planar system increases accuracy by automatically compensating for mounting and pitch-angle errors. The gained signal is converted to the desired dimension via an onboard RISC processor and then sent to the corresponding outputs. Featuring an effective operating range of $300 \mathrm{~mm}$ to $1,200 \mathrm{~mm}$, the Microstar Sensor can be used in applications demanding larger standoff distances without loss of accuracy [3, 4].

\section{Conditions and methodology of the measurement}

The experiment was carried out on 22. 09. 2015 at the Rosina airfield, located close to the town of Zilina. The surface conditions were: dry asphalt runway with the estimated 
adhesion factor of range $0.8-0.9$ and the runway temperature was of $31.4{ }^{\circ} \mathrm{C}$. The temperature of ambient air was $24{ }^{\circ} \mathrm{C}$ with very low speed wind so we could ignore its impact on the measurement. Prior to the experiment the calibration and test measurements to determine the necessary measurement characteristics (location of the braking manoeuvre, installation and calibration of the system, etc.) were carried out. The length of the experimental track was approximately $500 \mathrm{~m}$. A particular measurement inaccuracy was caused by the surface gradient estimated at $2 \%$.

The experiment was carried out by 10 independent drivers of a different age, praxis length and kilometres driven. Out of these 10 drivers, 8 were men and 2 were women. Each of the drivers had 10 attempts and the conditions were equal for all of them. Table 1 shows the overview of the individual drivers.

Table 1. Basic information about the drivers. Source: authors

\begin{tabular}{|c|c|c|c|c|}
\hline Driver & Gender & Age & $\begin{array}{c}\text { Praxis length } \\
\text { in years }\end{array}$ & $\begin{array}{c}\text { Approximate no. of } \\
\text { kilometres driven }\end{array}$ \\
\hline 1. & Man & 24 & 6 & 9,000 \\
\hline 2. & Man & 41 & 23 & 50,000 \\
\hline 3. & Man & 38 & 20 & 65,000 \\
\hline 4. & Man & 45 & 27 & 85,000 \\
\hline 5. & Man & 37 & 17 & 70,000 \\
\hline 6. & Woman & 25 & 4 & 3,000 \\
\hline 7. & Man & 33 & 15 & 60,000 \\
\hline 8. & Man & 29 & 11 & 100,000 \\
\hline 9. & Woman & 27 & 9 & 20,000 \\
\hline 10. & Man & 36 & 18 & 150,000 \\
\hline
\end{tabular}

After installation of the measuring device on the vehicle, the requested input data were set on the Correvit. System sampling rate was set to $200 \mathrm{~Hz}$, i.e. we had 200 data per second available.

A phenomenon in question was a full braking of the vehicle with the vehicle service brake, while the vehicle was equipped with ABS. The test driver drove the vehicle up to the desired speed $\left(50 \mathrm{~km} \cdot \mathrm{h}^{-1}\right)$. With the activation of the speed limiter fitted to a vehicle was achieved, that the vehicle did not exceed the speed. In about half of the departure runway the passenger activated a microwave sensor, and from that moment all important data were recorded. At the time of consistent desired speed of the vehicle the driver rapidly pressed the service brake pedal. This phenomenon was observed in the measuring system Correvit due to the location of the brake pedal sensor on the service brake, which was connected with this system. All other data were recorded in the memory of the evaluation unit and were available in a complete dataset of the program CeCallWin Pro. Braking was done to stop the vehicle till zero speed. In this state, when the vehicle was completely at rest, the measuring deactivated itself. After a short pause the next measurement was repeated.

\section{Processing of measured data}

The programme CeCallWin Pro 1.09.001 was used for the data evaluation. When used with the CeCalWin Pro Software, the Microstar Sensor functions as a complete data acquisition and evaluation system. The software functions enable test parameters and definitions to be permanently saved, along with online displays and evaluations, e.g. charts and plots. All measured data can be saved and evaluated off-line. 
Data obtained directly from an external memory of the evaluation unit are stored in the program CeCallWin Pro in the ADF format. With this software, the data are exported to TXT format (fig. 3), and then imported into Excel file [5].

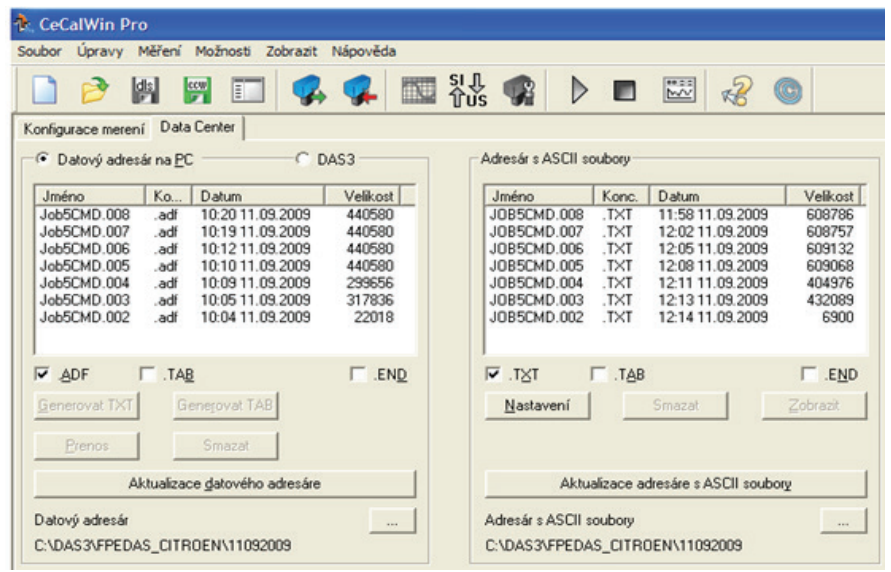

Fig. 3. Data export from ADF format to TXT format. Source: [5]

These data are clearly established in tabular form with the required parameters and it is possible to use them for future work. Data which were exported to the XLS file were: time, distance, speed, acceleration, respectively deceleration (each 0.005 seconds). Another important data point was an automatic indication of the commencement of braking, meaning the moment when a driver sharply pressed the brake pedal (in the Fig. 4 marked in yellow). Considering that a part of the experiment was the pursuit of the vehicle movement during the full braking deceleration, the start was set at this time point where I have added 0.2 seconds due to the technical specifications of the braking system (fully braking onset time + technical delays of brakes) and a time delay of a brake sensor (in the Fig. 4 marked in orange).

The end of the action was determined by the recorded stopping distance in Excel. The track has not changed, but measuring system still reported the movement of the vehicle. It means that because of the influence of centrifugal forces of the vehicle it was still swinging on the spot for a while (in the Fig. 4 marked in green). The individual kinematic data of the selected attempt are shown in Fig. 4. 


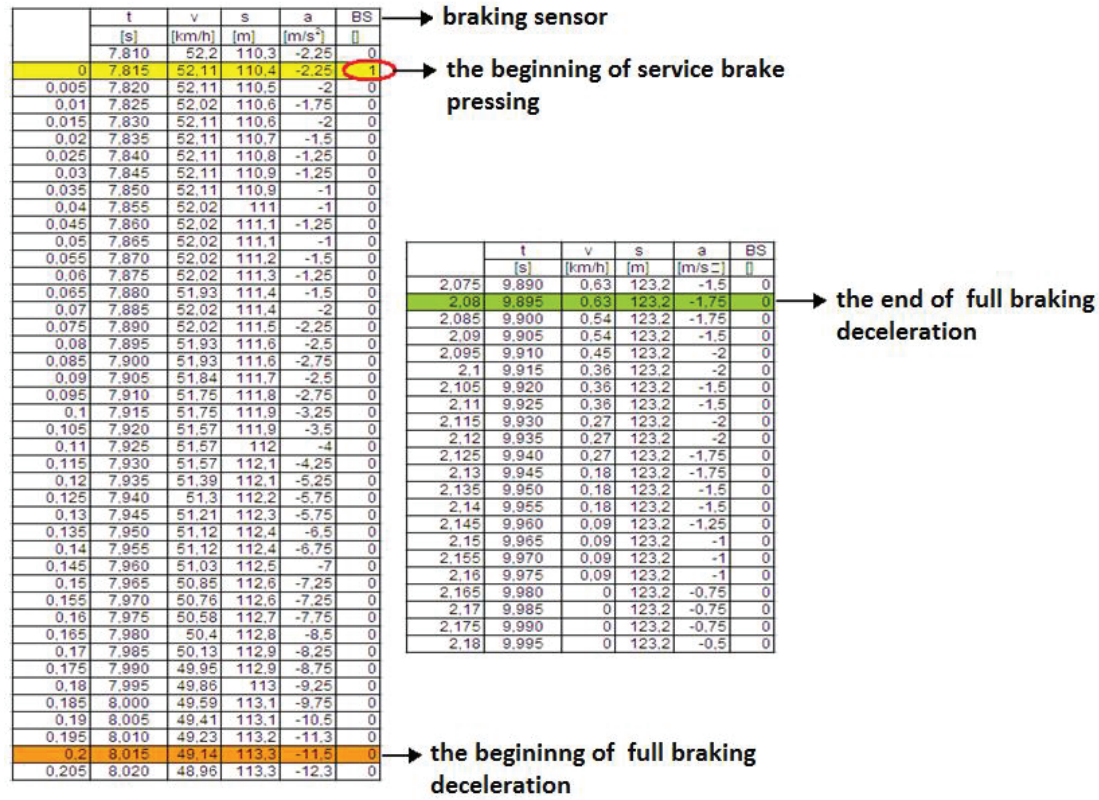

Fig. 4. Measured data view in MS Excel. Source: authors

The mean of fully braking deceleration in this case was calculated from the measured values of the stopping distance and speed using the relationship [6]:

$$
b=\frac{v_{1}^{2}}{2 . s}
$$

Where: $\mathrm{b}$ - mean of fully braking deceleration $\left[\mathrm{m} \cdot \mathrm{s}^{-2}\right]$,

$\mathrm{v}_{1}$ - the speed of the vehicle at the beginning of fully braking deceleration $\left[\mathrm{m} \cdot \mathrm{s}^{-1}\right.$,

$\mathrm{s}$ - distance travelled by the vehicle during the fully braking deceleration [m].

Relation (1) expresses the relationship to calculate the acceleration (deceleration) evenly accelerated (decelerated) movement.

\section{Measured data evaluation}

During each attempt the speed at the beginning of full braking deceleration, calculated mean of full braking deceleration, braking distance and time were evaluated. Some measurement attempts were not evaluated due to measuring equipment failure. This means that in some cases the measuring equipment did not measure the end of the measurement or the vehicle braking distance. Out of the 100 attempts 12 measurements were incorrect.

Due to the restricted range of this article we do not present the individual measurement results for each driver, but only their final average values. The highest average braking deceleration was reached by the driver no. 10 , precisely $9.61 \mathrm{~m} \cdot \mathrm{s}^{-2}$ (the driver with the highest number of kilometres driven $-150,000)$. On the other hand, the lowest braking deceleration was reached by the driver no. 3, precisely $9.07 \mathrm{~m} \cdot \mathrm{s}^{-2}$ (the driver with 65,000 $\mathrm{km}$ driven).

The average value of all average braking decelerations of the individual drivers was $9.38 \mathrm{~m} . \mathrm{s}^{-2}$. Furthermore, the minimum and the maximum values of the reached braking deceleration, and the standard deviation were calculated for each of the drivers (tab. 2). 
Table 2. Mean of full braking deceleration of the individual drivers. Source: Authors' calculations

\begin{tabular}{|c|c|c|c|c|c|c|}
\hline Driver & $\begin{array}{c}\text { No. of } \\
\text { incorrect } \\
\text { measure- } \\
\text { ments }\end{array}$ & $\begin{array}{c}\text { Min. value } \\
\text { of braking } \\
\text { deceleration } \\
{\left[\mathrm{m} . \mathrm{s}^{-2}\right]}\end{array}$ & $\begin{array}{c}\text { Max. value } \\
\text { of braking } \\
\text { deceleration } \\
{\left[\mathrm{m}^{-2} \mathrm{~s}^{-2}\right]}\end{array}$ & 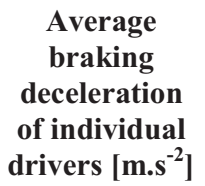 & $\begin{array}{c}\text { Standard } \\
\text { deviation of } \\
\text { individual } \\
\text { drivers }\left[\mathrm{m}^{\left.-\mathrm{s}^{-2}\right]}\right.\end{array}$ & $\begin{array}{c}\text { Average } \\
\text { value of } \\
\text { braking } \\
\text { deceleration } \\
{\left[\mathrm{m}^{-2} \mathrm{~s}^{-2}\right]}\end{array}$ \\
\hline 1. & 3 & 8.94 & 10.01 & 9.34 & 0.374 & \multirow{10}{*}{9.38} \\
\hline 2. & 2 & 9.10 & 10.60 & 9.44 & 0.489 & \\
\hline 3. & 0 & 7.68 & 9.85 & 9.07 & 0.597 & \\
\hline 4. & 3 & 9.02 & 9.70 & 9.46 & 0.227 & \\
\hline 5. & 1 & 7.69 & 10.22 & 9.54 & 0.689 & \\
\hline 6. & 1 & 9.05 & 9.77 & 9.35 & 0.211 & \\
\hline 7. & 1 & 8.77 & 9.78 & 9.46 & 0.298 & \\
\hline 8. & 0 & 8.64 & 9.82 & 9.25 & 0.316 & \\
\hline 9. & 1 & 8.50 & 10.11 & 9.32 & 0.494 & \\
\hline 10. & 0 & 9.11 & 10.08 & 9.61 & 0.296 & \\
\hline
\end{tabular}

Based on the above stated, we can observe that there are no major deviations among the calculated braking deceleration values. Also taking into account that some values were bigger or smaller that the calculated average, there was no major difference among the values. This was also statistically proved by the value of the standard deviation of the average braking deceleration, which is $0.146 \mathrm{~m} \cdot \mathrm{s}^{-2}$.

\section{Conclusion}

The result of the measurements is, that despite of the different age, length of the praxis and number of kilometres driven of the individual drivers, their final braking deceleration was only slightly different. The results were also not influenced by the gender of the driver. During the measurements we calculated the braking distance and the full braking deceleration from the moment of the full braking impact commencement. It is necessary to point out, that we did not consider the driver's reaction time, which is a factor essentially influencing the time and distance of the vehicle stopping. It would certainly be interesting to make a greater number of trials.

An important contribution of this experiment is the practical measurement of the braking behaviour of passenger car Kia Cee'd, in particular focus on the braking distances and average full braking deceleration. This value is very important for the Road Traffic Experts when elaborating the Forensic Expert's Reports of traffic accidents, where it represents the core entry value of braking behaviour of the respective vehicle; or alternatively in other areas, where the measured results can help to achieve the solution [7].

This contribution is the result of the project implementation:

2/KCMD/2017

Centre of excellence for systems and services of intelligent transport II, ITMS 26220120050 supported by the Research \& Development Operational Programme funded by the ERDF.

This paper is supported by the research project "From horse-drawn railway to intermodal transport" within Visegrad Fund. 


\section{References}

1. P. Hockicko, J. Ondruš, NTF 2012: proceedings of the conference, 214-217 (Brno: University of Technology Czech Republic, 2012)

2. DAS 3, Corrsys Datron, Available online: http://www.techtarget.com.br/portal/sites/default/files/cds-d_DAS-3_e.pdf (2007)

3. AB Dynamics, Corrsys-Datron Optical Sensors, Available online: http://www.abd-mfjp.com/item/corrsys/index_e.html (2017)

4. Correvit, Corrsys Datron Correvit SFII P User Manual Page 21, Available online: https://www.manualslib.com/manual/912858/Corrsys-Datron-Correvit-Sfii0P.html?page=21\#manual (2008)

5. Software CeCallWin Pro 1.09.001

6. J. Vrábel, B. Šarkan, T. Skrúcaný, Automotive safety 2016: problemy bezpeczeństwa w pojazdach samochodowych: X international science-technical conference, 383-388 (Kielce - Ameliówka, Wydawnictwo Politechniki Świetokrzyskiej, Poland, 2016)

7. J. Vrábel, et. al., Machines, technologies, materials: international virtual journal 8, 6 (2014) 